\title{
Locating Seismicity on the Arctic Plate Boundary Using Multiple-Event Techniques and Empirical Signal Processing
}

\author{
S. J. Gibbons ${ }^{1}$, D. B. Harris ${ }^{2}$, T. Dahl-Jensen ${ }^{3}$, T. Kværna ${ }^{1}$, T. B. Larsen ${ }^{3}$, B.
} Paulsen ${ }^{1}$, and P. H. Voss ${ }^{3}$

${ }^{1}$ NORSAR, P.O. Box 53, 2027 Kjeller, Norway. steven@norsar.no,

${ }^{2}$ Deschutes Signal Processing LLC, Maupin, Oregon, U.S.A.,

${ }^{3}$ The Geological Survey of Denmark and Greenland, Copenhagen, Denmark

\section{SUMMARY}

The oceanic boundary separating the Eurasian and North American plates between 70 and 84 degrees North hosts large earthquakes which are well recorded teleseismically, and many more seismic events at far lower magnitudes that are well recorded only at regional distances. Existing seismic bulletins have considerable spread and bias resulting from limited station coverage and deficiencies in the velocity models applied. This is particularly acute for the lower magnitude events which may only be constrained by a small number of Pn and Sn arrivals. Over the past two decades there has been a significant improvement in the seismic network in the Arctic: a difficult region to instrument due to the harsh climate, a sparsity of accessible sites (particularly at significant distances from the sea), and the expense and difficult logistics of deploying and maintaining stations. New deployments and upgrades to stations on Greenland, Svalbard, Jan Mayen, Hopen, and Bjørnøya have resulted in a sparse but stable regional seismic network which results in events down to magnitudes below 3 generating high quality Pn and Sn signals on multiple stations. A catalog of several hundred events in the region since 1998 has been generated using many new phase readings on stations on both sides of the spreading ridge in addition 
to teleseismic P phases. A Bayesian multiple event relocation has resulted in a significant reduction in the spread of hypocenter estimates for both large and small events. Whereas single event location algorithms minimize vectors of time residuals on an event-by-event basis, the Bayesloc program finds a joint probability distribution of origins, hypocenters, and corrections to travel time predictions for large numbers of events. The solutions obtained favour those event hypotheses resulting in time residuals which are most consistent over a given source region. The relocations have been performed with different 1-D velocity models applicable to the Arctic region and hypocenters obtained using Bayesloc have been shown to be relatively insensitive to the specified velocity structure in the crust and upper mantle, even for events only constrained by regional phases. The patterns of time residuals resulting from the multiple-event location procedure provide well-constrained time correction surfaces for single-event location estimates and are sufficiently stable to identify a number of picking errors and instrumental timing anomalies. This allows for subsequent quality control of the input data and further improvement in the location estimates. We use the relocated events to form narrowband empirical steering vectors for wavefronts arriving at the SPITS array on Svalbard for azimuth and apparent velocity estimation. We demonstrate that empirical matched field parameter estimation determined by source region is a viable supplement to planewave $\mathrm{f}-\mathrm{k}$ analysis, mitigating bias and obviating the need for Slowness and Azimuth Station Corrections (SASCs). A database of reference events and phase arrivals is provided to facilitate further refinement of event locations and the construction of empirical signal detectors.

\section{INTRODUCTION}

The nature and extent of the diverging Arctic plate boundary between the Eurasian and North American plates is revealed to a large extent by the location and properties of oceanic earthquakes. Engen et al. (2003) considered each of the segments of the plate boundary from 72 degrees North through to the Laptev Sea, performing a careful relocation of seismic events, an evaluation of source mechanisms, and integrating the seismological constraints with bathymetry, gravity and magnetic data. Oceanic seismicity is difficult to observe and constrain down to low magnitude due to the obvious complications of recording at local and near-regional distances. Despite the logistic difficulties of de- 
ploying and operating seismic stations at very high latitudes, parts of the Arctic plate boundary are now within a few hundred $\mathrm{km}$ of multiple land-based seismic stations. This provides an almost unique observational basis for oceanic seismicity, allowing detection and location of events down to considerably lower magnitude than is possible for most other regions of diverging plate boundary. Fig. 1 displays event locations calculated by Engen et al. (2003) together with the locations of seismic stations comprising the current European Arctic network. This bulletin covers the years 1955-1998 and predates a significant improvement to the regional network, both in terms of the number of stations and the capability of those stations. It is our aim to assess the improvement in our image of seismicity in this part of the world given (a) an improved observational network, (b) advances in event location algorithms, and (c) advances in seismic signal processing.

The seismic network displayed in Fig. 1 contains both new stations and legacy stations which have been upgraded. Fig. 2 displays the periods for which digital data from each station is available from open sources. Some stations operated as analog observatories prior to this time, including the WWSSN stations KEV and KBS (Oliver \& Murphy 1971). The SUMG station on Greenland belongs to the GEOFON network with the remaining Greenland stations being part of the National Seismic Network of Denmark. The station DAG (Danmarkshavn) is jointly operated by GEOFON and the Geological Survey of Denmark and Greenland (GEUS). Other stations belong to the Norwegian National Seismic Network which, at the start of the period displayed, provided largely short-period triggered data but, since around 2009, are now modern broadband stations providing continuous data (Demuth et al. 2016). The ARCES and SPITS arrays are small aperture seismic arrays designed for optimal detection and location of weak seismic events at regional distance (e.g. Mykkeltveit et al. 1990) and, due to the enhanced detection and parameter estimation capability of seismic arrays (Douglas 2002; Schweitzer 2014), provide an exceptionally low detection threshold. The upgrade to SPITS in 2004 from being vertical only (with a single 3-C sensor) to a 3-component broadband array has improved the regional monitoring significantly given far greater detection capability for regional S-phases (Gibbons et al. 2011).

Many of the stations displayed in Fig. 1 are now part of the Greenland Icesheet monitoring network (GLISN: Clinton et al. 2014) and upgrades in this context led to real-time transmission of broadband data from stations on Greenland which had previously required annual physical retrieval of data. The location resolution of the network on the Svalbard archipelago has been improved greatly by the additional new stations HSPB (Wilde-Piórk et al. 2009) and BRBB (Asming et al. 2013) on the West coast of Spitsbergen. The extended mini-network is increasingly capable of low-threshold seismic monitoring of both tectonic (e.g. Pirli et al. 2013; Junek et al. 2015) and glacial (e.g. Köhler et al. 2015) sources on and close to Svalbard. The significance of the improvement in the global seismic 
monitoring capability is also not to be underestimated. The International Monitoring System (IMS) for verifying compliance with the Comprehensive Nuclear-Test-Ban Treaty (CTBT) became operational shortly after the period of seismicity studied by Engen et al. (2003). Fig. 3 displays the seismicity in the region of interest together with the regional network and IMS stations at far-regional and teleseismic distances. The IMS contains numerous arrays, with demonstrable superiority in detection capability (e.g. Kværna \& Ringdal 2013), many of which have been built in the past two decades. In addition, the teleseismic azimuthal coverage provided by the IMS for this source region in the Northern Hemisphere is superb and this increases the likelihood of high epicenter accuracy based on network criteria (e.g. Bondár et al. 2004).

Knowledge of the velocity structure of Earth has improved significantly both on global and local scales. Of the bulletins considered by Engen et al. (2003), one of the reasons that the Engdahl et al. (1998) catalog was prioritized was that it refined the best solutions of the International Seismological Center (ISC) with the ak135 velocity model (Kennett et al. 1995) which had recently become the workhorse for global event location. Two decades later, ak135 has not been superceded and the greatest challenge has become the correct representation of the 3-dimensional departures from this optimal radial velocity structure. The traveltime residuals for seismic phases are significantly greater for regional arrivals than teleseismic (e.g. Myers et al. 2015) and much of the spread in maps of seismicity down to low magnitudes is likely to result from bias introduced by deficiencies in the traveltime predictions for regional phases. One successful approach is to derive source-specific station corrections (e.g. Murphy et al. 2005), although subsequent development of global 3D velocity models has also been rapid (Myers et al. 2010; Simmons et al. 2012, 2015; Ballard et al. 2016). 3D models in largely aseismic regions such as the Barents Sea are challenging to calibrate and evaluate and typically are constructed using multiple geophysical datasets (e.g. Bungum et al. 2005; Hauser et al. 2011). Indeed it can be demonstrated that there may still be value in calculating revised 1-D velocity models for the crust and uppermost mantle, applicable to extended regions with limited calibration events (e.g. Gibbons et al. 2016). More locally, seismic refraction profiles (e.g. Czuba et al. 2008; Jokat et al. 2012) have provided significantly improved regionalized velocity models of sections of the Arctic Plate Boundary which have increased the earthquake hypocenter estimate accuracy for near-regional studies (e.g. Schlindwein et al. 2013).

Focusing on the time period starting after that considered by Engen et al. (2003), we examine the extent to which we can locate seismicity on the region of the plate boundary indicated in Fig. 3 using the permanent regional network and supplementary teleseismic phases. It is not the intention to generate a comprehensive bulletin; available catalogs have been examined and an extensive selection of events relocated. It is the broad-scale picture of seismicity which is of interest. Does the 
scatter observed in the existing bulletins represent the true spatial distribution or can the scatter be reduced using enhanced consideration of the same seismic data? Five decades since Douglas (1967) demonstrated how deviations from predicted traveltimes could be compensated for by consideration of several events simultaneously, we have various alternatives for large-scale multiple event location. Nooshiri et al. (2017) provide an extension of the shrinking-box source specific station term (SSST) method (Richards-Dinger \& Shearer 2000; Lin \& Shearer 2005) which provides a reduction in traveltime residuals (both regional and teleseismic) for multiple events in a complex tectonic environment using station correction terms. The Bayesloc program (Myers et al. 2007, 2009) employs a Bayesian hierarchical method to solve for the joint probability of hypocenters and origin times, traveltime corrections and pick uncertainties, and phase labels. Both of these procedures generate estimates of traveltime corrections as output parameters.

In the CTBT context, seismic event location is performed using a relatively sparse network of stations in which seismic arrays dominate. The location procedures currently employed at the International Data Center (IDC) in Vienna employ an extension of the algorithm of Bratt \& Bache (1988) whereby the inversion of arrival times is augmented by slowness and backazimuth measurements from array analysis. The relative significance of the backazimuth measurements will depend upon the station coverage and the set of additional available constraints. The HYPOSAT routine (Schweitzer 2001a), for example, allows fine-tuning of the weighting of different arrival time, backazimuth, and slowness parameters. The backazimuth of an incoming wavefront on a seismic array can often deviate significantly from the great circle path from the source (e.g. Berteussen 1976) and correction for measurement bias can improve location estimates greatly (Schweitzer 2001b). In the same way that source-specific traveltime corrections have been applied to arrival times, Slowness and Azimuth Station Corrections (SASCs) have been calibrated and applied to IMS stations both for regional distances (e.g. Ben Horin et al. 2004) and teleseismic (e.g. Bondár et al. 1999). The problem is often complicated additionally by a frequency dependence of the slowness and apparent velocity estimates (e.g. Kværna \& Doornbos 1991; Gibbons et al. 2010) which is difficult to correct for explicitly, since the frequency band available for processing will vary from signal to signal as a function of signal-to-noise ratio (SNR) and spectral content.

Matched Field Processing (MFP) is a narrow band method for characterizing the spatial structure of a signal propagating in heterogeneous environments (Baggeroer et al. 1993). Its original application in underwater acoustics was possible given that models of sound velocity in the oceanic waveguide are accurate enough to calculate narrow-band Greens functions, allowing coherent processing of nonplanar wavefronts from a given source on a receiver array. In seismology, we are in general unable to calculate Greens functions for high frequency regional signals since the forms of these signals are 
determined by geological structure at spatial scales currently inaccessible to modelling (Harris et al. 2012). However, Harris \& Kvaerna (2010) demonstrated that sources of repeating seismicity (such as open-cast quarries) generated patterns of phase shifts on seismic sensor arrays that were highly repetative, even given a significant departure from the plane-wave approximation of the wavefield. Matching the set of phase shifts observed for a given incoming wavefront with those measured from previously observed events at different sites allowed a regional seismic array to successfully identify the sources of signals even given sources that were more closely spaced than the array could theoretically resolve. This approach is referred to as Empirical Matched Field Processing (EMFP). While the goal of Harris \& Kvaerna (2010) was to distinguish between different sources, we here investigate if empirical signal templates taken from well-located events in a continuous band of seismicity are able to provide unbiased direction estimates for incoming wavefronts on arrays which mitigate the problems of azimuth bias in classical f-k analysis. In particular, the narrowband nature of EMFP means that the calibration is performed separately for many narrow frequency bands, such that the frequency dependence of the parameter estimates will be corrected for implicitly. An accurate backazimuth estimate may be crucial to a correct event hypothesis for a low magnitude event.

In section 2 we provide an overview of a number of different event bulletins for recent seismicity in this particular region and discuss how and why they differ. We also introduce the set of events used in this paper to investigate location performance, for which many new readings have been made on the regional network. In section 3, we describe the results of the multiple event Bayesian hierarchical event location program Bayesloc - and demonstrate why this procedure may lead to a significantly more accurate event bulletin for the region. Section 4 reviews slowness and azimuth estimation for incoming wavefronts on seismic arrays and discusses whether a refined event catalog can be exploited to identify the source location of detected wavefronts using EMFP. Finally, we discuss prospects for extending and further enhancing the quality of event catalogs for the region both using multiple event techniques and empirical signal detectors.

\section{OVERVIEW OF SEISMIC BULLETINS OF RIDGE SEISMICITY}

Panels a), b), and c) of Fig. 4 display selected hypocenter estimates on our chosen section of the plate boundary taken from three different openly available catalogs. Panel a) displays relocations in the ISC catalog, b) displays solutions from the Reviewed Event Bulletin (REB) of the IDC, and c) displays solutions from the NORSAR regional event bulletin; each of these catalogs are described in greater detail in the following three paragraphs. The final panel (d) contains fixed-depth relocations of 730 events which have been selected from these three different sources and reanalyzed using data from the network displayed in Fig. 1. To make a comparison between panels a), b) and c) more meaningful, 
we have limited the hypocenters displayed to events which are also displayed in panel d). The sets of events displayed in the first three panels are not identical for reasons of network conditions and location procedures.

The NORSAR regional event bulletin (Fig. 4 c) took its current form in 1998 although the number of stations used in the analysis has increased significantly over the years. The apparent uncertainty in some event location estimates is likely to be at least as much a function of the year in which the event took place as the number of existing seismic recordings. The original intention was that only the array stations operated by NORSAR would be used, together with the arrays HFS (Sweden), FINES (Finland), and APA (Russia) for which bi-lateral agreements had been made. Events in this region prior to 2001 are likely only to use regional P and S phase readings at ARCES and SPITS. The larger events, also recorded at the arrays in southern Fennoscandia, may have had more phase readings but, given the poorer traveltime predictions at these far-regional distances (e.g. Myers et al. 2015), were not necessarily much better constrained. In 2001 the data from the open KBS station was added, improving the location estimates along and North West of the Knipovich Ridge significantly. The 2004 upgrade to the SPITS array made significant improvement to the reliability of regional S-arrivals at this station and, in recent years, the addition of stations HSPB, BRBB, HOPEN, BJO1, DBG, and NOR to the analysis has led to far better constraints on events. The solutions are not constrained by teleseismic phases.

The REB solutions (Fig. 4 b) use exclusively readings from IMS stations. In addition, there are conditions regarding the number of stations required to define an event: rules that do not apply to the NORSAR solutions. The SPITS array is a so-called auxilliary station which means that it cannot be used for detection purposes at the IDC: only for better constraining events. Given the IMS network geometry, REB events on the Arctic Plate Boundary are necessarily recorded out to far-regional and, typically, teleseismic distances. The NORSAR reviewed bulletin is, in general, restricted to events exceeding magnitude 2. While there is in principle no lower magnitude limit for the REB, the event definition criteria mean that the detection threshold for this region is about magnitude 3 . As an example, the REB contains four events from the Svalbard region on February 21, 2008, including the M 5.9 Storfjorden main shock (Pirli et al. 2010). On the same day, the NORSAR regional reviewed bulletin contains 66 events from the same region. Most of the ridge REB events have depth fixed to zero.

The ISC relocations (Fig. 4 a) result from a reprocessing of phase readings from all contributing seismological observatories, now including the IDC. (All origins and arrivals from the REB are now available via the ISC.) Recent decades have seen significant improvements in the procedures carried out at the ISC and a definitive description of current processes is provided by Bondár \& Storchak 
(2011). With poor depth constraints, most ISC relocations are also fixed in depth with $10 \mathrm{~km}$ being favoured.

Fig. 4 d) displays a set of events relocated using HYPOSAT using the Fennoscandian 1-D velocity model (FESCAN: Mykkeltveit \& Ringdal 1981) and depth fixed to $20 \mathrm{~km}$. This set of events is not intended to be a comprehensive bulletin and a number of large events were omitted due to, for example, interfering signals, data dropouts, and timing errors on key stations. The primary selection criterion was that the events had clear regional $\mathrm{P}$ and $\mathrm{S}$ onsets at several of the network stations displayed in Fig. 1. A minimum requirement was 6 phases, including the first P-arrival at SPITS. (Only events recorded by the SPITS array were considered so that the empirical signal processing study in Sec. 4 could utilize all events in the dataset.) It was the intention to record the times of the first $\mathrm{P}$ and the first $\mathrm{S}$ arrival from each station for which these phases were visible. Given the distances from most events to the stations of the regional networks, these phases are almost always Pn and $\mathrm{Sn}$. The readings from these stations were also strictly limited to the first $\mathrm{P}$ and first $\mathrm{S}$ arrivals. As is typical for oceanic paths, Lg for ridge events is mostly blocked (Baumgardt 2001) such that first S-arrivals are almost always unambiguously identified as Sn. The accuracy in onset time estimation for later parts of the wavetrain, such as Pg and Lg, is typically poorer than for the first P- and S- arrivals and so such phases were omitted from this study. Conversions between Lg and Sn at the ocean-continent boundary (e.g. Campillo 1987; Furumura et al. 2014) are unlikely to be an issue for the paths considered in this paper since the direct Sn phase arrives ahead of the converted energy at the distances considered. The phase arrivals for each event were augmented by teleseismic P arrivals from the REB with SNR exceeding 3.0. A few events in 2006 applied a time-correction to the KBS station defined by Gibbons (2006); all other clear timing errors resulted in the station being excluded. A major part of the relocation work was the picking of arrivals on stations which had not been used previously in the NORSAR bulletin. This was particularly significant for the Greenland stations, but also applied to, e.g. KBS, BRBB, HSPB, BJO1, and HOPEN in the time before these stations were included in the NORSAR analysis.

The primary conclusion from Fig. 4 is that, despite the different attributes of the different bulletins, the spread in hypocenter estimates does not differ greatly. The REB solutions arguably resolve the transform fault zones north of Svalbard best but, with the dominance of teleseismic phases, this is to be expected. Despite increasing the number of regional phases significantly, and improving the azimuthal coverage in almost all cases, the relocations in panel d) do not result in a reduction of the scatter in hypocenter estimates. 


\section{A BAYESIAN RELOCATION OF RIDGE SEISMICITY}

The close proximity to each other of events along the plate boundary, including earthquakes wellrecorded globally, suggests that a multiple event method which exploits clustering may be able to improve the resolution of earthquake catalogs for the region. The Bayesloc program has demonstrated excellent performance over broad regions with abundant seismicity (e.g. Myers et al. 2011) and we attempt to locate the set of events displayed in Fig. 4 d). We perform two separate runs of Bayesloc, each with a different velocity model for the crust and uppermost mantle. One model is FESCAN (Mykkeltveit \& Ringdal 1981) and the other is BAREY (Hicks et al. 2004), optimized for wellconstrained traveltimes in the Barents Sea region. For comparison, single event location estimates were made for each event using each of the velocity models. All location estimates use exactly the same set of arrival time measurements.

The results of the single and multiple event locations are displayed in Fig. 5 with a remarkable increased sharpness to the epicenter distribution associated with the multiple event locations. Aside from the universal reduction in the width of the seismicity band, we resolve transform fault zone features north west of Svalbard such as the Molloy Ridge (see Engen et al. 2003) and seismic gaps such as that beneath the Logachev Seamount (Schlindwein et al. 2013). At least as significant for the level of confidence in the new multiple event locations is that the FESCAN and BAREY epicenter estimates are almost always distinct for the single event locations and almost always coincident for the multiple event locations. This is displayed more clearly in panels c) and d) of Fig. 5.

To understand the improvement in the spread of epicenters provided by the multiple-event location, we consider each of the event hypotheses generated one by one, and predict the arrival time for each associated phase using the applied velocity model. Fig. 6 displays the (observed minus predicted traveltime) residual for the initial P-arrival at the KBS station for each of the four sets of event origin estimates displayed in Fig. 5. Panels a) and b) display the KBS first P-arrival residual when the FESCAN model is applied, for the single-event and multiple-event procedures respectively. For the single-event location estimates (Fig. 6 a), in any given source region, there are events for which this particular traveltime is overestimated and events for which it is underestimated. For the Bayesloc output (Fig. 6 b) the residuals vary exceptionally smoothly along the path of the plate boundary, indicating faster-than-predicted to the South and slower-than-predicted to the North. Panels (c) and (d) display equivalent plots for the solutions obtained using the BAREY velocity model. A similar pattern is observed but with marginally brighter colours in panel (d) than in panel (b) - suggesting that the FESCAN model may be more applicable to the indicated paths than the BAREY model. The few spots showing intense colours in panels (b) and (d) are almost certainly anomalous arrival times (resulting either from a picking error or a timing error) or mislocations (indicating erroneous entries elsewhere in 
the input data). These outliers are clearly identifiable from the Bayesloc residuals but are quite typical of residuals from the single-event solutions. As with the SSST locations of subduction zone seismicity presented by Nooshiri et al. (2017), Bayesloc is providing a probability distribution for traveltime corrections which compensates for inadequacies in the predicted 1-D velocity model.

Fig. 7 displays equivalent plots for three different phases for the BAREY model Bayesloc solutions. The crucial observation is that, for the multiple-event location estimates, the traveltime residual distributions vary smoothly for all phases even though the exact dependences vary from phase to phase. Our input velocity models do not accurately represent the 3-dimensional structure, but the Bayeslocestimated departures from the assumed 1-d velocity model appear to be represented consistently.

In the supplementary material, we provide input files for the Bayesloc program considering all events from the dataset here with at least 8 phase arrivals. All necessary files are provided for the FESCAN velocity model calculation, allowing reproduction of the results and further experimentation.

\section{EMPIRICAL DIRECTION OF ARRIVAL ESTIMATION}

Array stations form the backbone of the seismic IMS network and the detection capability for the European Arctic is to a large extent governed by the SPITS and ARCES seismic arrays. The improvement in detection capability results from the ability to perform delay-and-stack beamforming which increases SNR. Once a detection has been made, phase association and event hypothesis generation are significantly enhanced by estimates of backazimuth $\left(\Theta\right.$, a direction) and apparent velocity ( $v_{\text {app }}$, primarily for phase identification). In the estimation process, these parameters are coded in the slowness vector, $s$, defined by

$$
\boldsymbol{s}=\left(s_{x}, s_{y}\right)
$$

with

$$
\begin{aligned}
& s_{x}=s \sin (\Theta), \\
& s_{y}=s \cos (\Theta),
\end{aligned}
$$

and

$$
s=1 / v_{\text {app }}
$$

If $\boldsymbol{x}_{j}$ denotes the coordinates of sensor $j$, relative to the array reference site, then we denote the timeseries recorded at this site by $r\left(t, \boldsymbol{x}_{j}\right)$.

For a given frequency $\omega$, for an array with $N$ sites, the steering vector

$$
\boldsymbol{\varepsilon}(\omega, \boldsymbol{s})=\left[\begin{array}{lll}
e^{-i \omega \boldsymbol{s} . \boldsymbol{x}_{1}} & \ldots & e^{-i \omega \boldsymbol{s} . \boldsymbol{x}_{N}}
\end{array}\right]^{T}
$$


allows a measurement of the energy incident on the array consistent with the plane wavefront hypothesis, $s$, using

$$
P(\omega, s)=\left|\int \sum_{j=1}^{N} r\left(t, \boldsymbol{x}_{j}\right) e^{i \omega\left(t-\boldsymbol{s} . \boldsymbol{x}_{j}\right)} d t\right|^{2}=\boldsymbol{\varepsilon}(\omega, \boldsymbol{s})^{H} \boldsymbol{R}(\omega) \boldsymbol{\varepsilon}(\omega, \boldsymbol{s})
$$

where $H$ denotes the Hermitian transpose, and $\boldsymbol{R}(\omega)$ the covariance matrix. $P$ can be written

$$
\begin{aligned}
P(\omega, \boldsymbol{s}) & =\left(\int \sum_{m=1}^{N} r\left(t, \boldsymbol{x}_{m}\right) e^{i \omega\left(t-\boldsymbol{s} . \boldsymbol{x}_{m}\right)} d t\right)\left(\int \sum_{n=1}^{N} r\left(t^{\prime}, \boldsymbol{x}_{n}\right) e^{i \omega\left(t^{\prime}-\boldsymbol{s} \cdot \boldsymbol{x}_{n}\right)} d t^{\prime}\right)^{*} \\
& =\sum_{m=1}^{N} \sum_{n=1}^{N} e^{-i \omega \boldsymbol{s} .\left(\boldsymbol{x}_{m}-\boldsymbol{x}_{n}\right)} R_{m n}(\omega)
\end{aligned}
$$

where

$$
R_{m n}(\omega)=\int d t \int d t^{\prime} w(t) r\left(t, \boldsymbol{x}_{m}\right) w\left(t^{\prime}\right) r\left(t^{\prime}, \boldsymbol{x}_{n}\right) e^{i \omega\left(t-t^{\prime}\right)}
$$

and $w(t)$ is a window function used to isolate a waveform segment (phase) of interest. $w(t)$ is one during the segment time interval and zero elsewhere. Setting $\tau=t^{\prime}-t$ and $\gamma=t$ we can express the elements of the spatial covariance matrix

$$
\begin{aligned}
R_{m n}(\omega) & =\int d \tau \int d \gamma w(\gamma) r\left(\gamma, \boldsymbol{x}_{m}\right) w(\gamma+\tau) r\left(\gamma+\tau, \boldsymbol{x}_{n}\right) e^{-i \omega \tau} \\
& =\int d \tau c_{m n}(\tau) e^{-i \omega \tau}
\end{aligned}
$$

where $c_{m n}(\tau)$ is the correlation function between recorded waveform segments at two stations:

$$
c_{m n}(\tau)=\int d \gamma w(\gamma) w(\gamma+\tau) r\left(\gamma, \boldsymbol{x}_{m}\right) r\left(\gamma+\tau, \boldsymbol{x}_{n}\right)
$$

Given the transience of the coherent part of the wavefield for the high frequency regional arrivals of interest, we wish to evaluate the covariance matrix, $\boldsymbol{R}(\omega)$, using very short data windows (typically of the order 3 seconds). The multitaper coherence routines provided by Prieto et al. (2009) provide extremely stable estimates of narrowband coherence and phase difference.

When estimating the slowness vector, $s$, which best fits the incoming wavefront, it is typical to evaluate a normalized relative beam-power function of the form

$$
\hat{P}(s)=\frac{\sum_{k} \boldsymbol{\varepsilon}\left(\omega_{k}, \boldsymbol{s}\right)^{H} \boldsymbol{R}\left(\omega_{k}\right) \boldsymbol{\varepsilon}\left(\omega_{k}, \boldsymbol{s}\right)}{\sum_{j} \operatorname{tr}\left\{\boldsymbol{R}\left(\omega_{k}\right)\right\}}
$$

over a grid of slowness space and summed (incoherently) over a wide range of frequencies $k$.

It became clear in the very early days of operating the SPITS array that the backazimuth estimates obtained showed significant deviation from the great circle backazimuth (Schweitzer 2001b), largely consistent with a dipping structure below the array. Gibbons et al. (2011) considered an extended database of seismicity and demonstrated a very complex relationship between the apparent velocity estimates and the great circle backazimuth, with events to the north west generating both Pn and Sn 
arrivals which are recorded on the SPITS array with teleseismic apparent velocities. The Bayesloc relocations considered in the previous section provide an excellent database with which to examine the backazimuth measurement anomalies since, unlike the REB or NORSAR reviewed solutions, all of these hypocenter estimates are entirely independent of the slowness vector estimates on SPITS.

Fig. 8 shows the backazimuth and apparent velocity measured on a 3 second long window in the 2-8 Hz band for the first P-arrival at SPITS for each of the Bayesloc-relocated events as a function of the great-circle backazimuth. There is a degree of scatter to which many factors contribute. Firstly, there is the intrinsic complication of fitting an ideal plane wavefront to a receiver array in heterogeneous geology for which the elevation differences between receivers is significant. (Gibbons et al. 2011, demonstrate the extent to which the estimated backazimuth can be influenced by consideration of elevation differences.) Secondly, the $2-8 \mathrm{~Hz}$ band is a broad band and, depending upon the spectral content of the signal, signals of different dominant frequencies may show preference to different backazimuth and apparent velocity estimates. Thirdly, issues of data quality - SNR, missing channels, possible timing error on individual channels - may affect the backazimuth measurement adversely. Fig. 8 confirms the increase in the apparent velocity as we move northwards along the plate boundary and confirms that an azimuth bias of 30 degrees and more exists for certain directions. (The azimuth and slowness deviations displayed in Fig. 8 are consistent with the vector mislocations calculated by Koch \& Kradolfer 1999, in preparation for IDC operations.)

Instead of assuming a plane wavefront slowness vector $s$, we can calculate a spatial covariance matrice, $\boldsymbol{R}$, from a seismic arrival known to have originated from a given source location. The principal eigenvector of this covariance matrix, $\boldsymbol{R}$, can be used as an empirical steering vector $\varepsilon(\alpha)$ where the $\alpha$ denotes the seismic event or a very limited source region.

The estimates of the relative power for each of candidate plane wavefronts, $s$, given by Eq. 6 can be augmented by empirical matched field statistics

$$
\hat{P}(\alpha)=\frac{\sum_{j} \varepsilon\left(\omega_{j}, \alpha\right)^{H} \boldsymbol{R}\left(\omega_{j}\right) \varepsilon\left(\omega_{j}, \alpha\right)}{\sum_{j} \operatorname{tr}\left\{\boldsymbol{R}\left(\omega_{j}\right)\right\}} .
$$

Fig. 9 displays matched field statistics of the form in Eq. 14 evaluated for the P-arrival displayed where each of the $\varepsilon\left(\omega_{j}, \alpha\right)$ is obtained as the principal eigenvector of the covariance matrix evaluated for the first arrival from the event at the location indicated. The true location of the event is just North of Jan Mayen but, due to azimuth bias at the receiver array, appears to come from a direction over 10 degrees further to the South than the true backazimuth. The empirical matched field statistics reach a maximum close to the true backazimuth and decrease slowly as the azimuth deviation increases. The resolution in this broadband matched field calculation is comparable to the resolution offered by the plane wavefront $\mathrm{f}-\mathrm{k}$ analysis; only the bias is eliminated. 
Fig. 10 (panel a) displays the azimuth residual calculated using classical $\mathrm{f}-\mathrm{k}$ analysis as a function of the epicentral backazimuth for each of the events (this is to say how much in error the black line of Fig. 9 is from the great circle backazimuth). Fig. 10 (panel b) displays the residual calculated using the empirical matched field statistics (this is to say how much in error the red line of Fig. 9 is from the great circle backazimuth). A backazimuth estimated for a given arrival at SPITS using the empirical steering vectors is almost certain to be within 10 degrees of the true backazimuth and, in the majority of cases, within 5 degrees. The spread in the residuals for a given source region is quite similar for the plane-wave (panel a) and empirical (panel b) calculations, again as we might expect given that the same window length and frequency band are used for both calculations. However, the empirical calculations eliminate the bias.

In figures 9 and 10 we have simply taken a single backazimuth estimate, corresponding to the location estimate for the event with the best match. As we see in Fig. 9, there is often little to differentiate between the values of the matched field statistics obtained using different steering vectors and a regionally averaged estimate may give a better direction indication. Considering a longer time-window or a different frequency band, focusing on higher frequencies, may differentiate more between the different source regions. Alternatively, empirical steering vectors calculated from ensemble covariance matrices calculated for many events in a concentrated region (Harris \& Kvaerna 2010) may give a more robust estimate. The wide spread in the estimates is very much a consequence of the very small aperture of the SPITS array, with the resulting limitations in slowness resolution; a larger aperture array is likely to provide a higher resolution.

The matched field slowness estimate is exactly that; we do not map uniquely into geographical space with this single phase. The great circle path towards the true location of the event crosses the plate boundary twice and, from the EMFP statistic alone, we cannot differentiate between the two candidate source regions. It is worth noting that all contributions to the observed phase shifts between signals on the different sensors are corrected for implicitly by the EMFP estimates. This includes elevation differences, such that no assumptions about the local wavespeed at the array need to be made.

\section{CONCLUSIONS}

The network of seismic stations in the North Atlantic region has improved significantly in the past two decades and we have exploited this regional data to evaluate the distribution of seismicity along the Arctic Plate Boundary between 70 and 84 degrees North. Augmenting this data with teleseismic phases where available, and applying the Bayesian multiple event location routine Bayesloc, we have demonstrated a significant improvement over both existing seismic event bulletins and single-event 
locations using the same input data. The principal reason for the success of the procedure is the calculation of the probability distribution of traveltime corrections. These are particularly significant for the regional phases, with residuals of up to several seconds for some regional S-phases. A single-event algorithm, without access to this contextual information, will attempt to minimize a residual vector norm and the optimal residual is highly sensitive to the set of phases present and the predicted traveltime for each phase using the selected velocity model. The Bayesloc solutions are remarkably robust to small changes in the applied velocity model.

This study has focused on events along a specially chosen section of the plate boundary. The primary reason for this initial choice was to try to have reasonable azimuthal coverage both with the teleseismic and regional networks. Ultimately we seek to extend the procedure applied both south of Jan Mayen and north of 84 degrees North, although the network considerations in these sections will be somewhat different. Improvements in the seismic network across the European Arctic have led to an increased monitoring capability over an extended region (Antonovskaya et al. 2014). Seismicity on the Gakkel Ridge, north of Svalbard, has been analyzed teleseismically (Engen et al. 2003; Korger \& Schlindwein 2012), locally (Korger \& Schlindwein 2013), and now with an improved prospect of monitoring with permanent regional stations (Morozov et al. 2016). There is more diffuse seismicity along the coast of Greenland, on and around Svalbard and, for example, between the spreading ridge and the Continental Ocean Transition near Bear Island (Czuba et al. 2011). These regions have far fewer seismic events recorded well teleseismically and, with fewer very tightly constrained events, Bayesloc may be less able to mitigate bias in the regional traveltimes. However, as the number of seismic events recorded increases, the basis for successful cluster-oriented, context-based location algorithms will only improve.

We have demonstrated that, using the best relocations as a reference basis, we can estimate the apparent velocity and backazimuth of phase arrivals on seismic arrays using Empirical Matched Field Processing. This direct mapping from source region to slowness space corrects implicitly for deviations to the incoming wavefield resulting from geological heterogeneity along the path and close to the array. These estimates avoid the need to correct for the large biases associated with plane-wave estimates and will be less sensitive to the spectral content of signals. At this stage we advocate employing empirical signal estimation into seismic pipeline processes for measuring the properties of phases detected on single stations. The significance of the backazimuth estimates on the SPITS array is greatest for low magnitude events which are detected at few stations.

The process is likely to be most effective for seismic arrays since the time-series on different sensors are likely to be highly coherent but differing by a characteristic phase shift, which is encoded in the empirical steering vectors. EMFP can, in principle, be applied to single 3-compoenent sensors 
with the covariance matrices evaluated between the different components, although the performance is likely to be significantly poorer at low SNR (Harris 1990). Empirical signal detectors have been used to great effect at classifying tectonic activity near Svalbard (Junek et al. 2015) and EMFP has been demonstrated to provide a significantly improved detection and location capability for seismicity in a geothermal field (Wang et al. 2015). However, the performance of such fully empirical classification of seismicity will improve significantly with improvement in the underlying catalog basis. The improvement that the Bayesloc solutions provide over the existing catalogs give good reason to optimize the basis catalog using multiple event location techniques prior to attempting completely empirical classification of seismicity.

We advocate an iterative approach to refining the image of seismicity. Having run Bayesloc, we believe it necessary to calculate and evaluate all residuals between the observed and predicted traveltimes. The spread in the distribution of residuals for a given region is sufficiently reduced by Bayesloc that significant outliers from picking and timing errors can be identified and excluded with relative ease. (Residual values which are clear outliers from the residual distribution for the multiple event location estimates are well within the standard deviations for the single event location estimates.) After an evaluation of residuals, a new relocation can be attempted. The runs of Bayesloc demonstrated here (and provided in the supplementary material) are performed without imposing tight priors on any individual events. This may be possible for some events constrained by, for example, temporary OBS deployments (e.g. Schlindwein et al. 2013). While the relocations calculated in the current study use both regional and teleseismic phases, the teleseismic phases used are limited to those reported in the REB (and therefore limited to IMS stations). The constraints on some larger events may be improved further by using carefully screened teleseismic phases from non-IMS stations. Depth is not well-constrained using the phase information provided here; additional constraints from OBS studies or depth phases (e.g. Letort et al. 2014) may provide additional priors.

Single-event location estimates are still the standard procedure at data centers producing seismic bulletins. Quoted formal location uncertainties are frequently far too optimistic, failing to accurately incorporate bias and uncertainty in the applied velocity model (e.g. Billings et al. 1994). We demonstrate here that the bias for a given phase for events from a limited geographical source region is often significant and yet well-constrained in the output from the multiple event location procedure. However, this bias is not accounted for in generic location procedures at seismological observatories and the true location uncertainty for a given event is part of a truly joint probability depending also upon the constraints which apply to other nearby seismic events. If routine seismic bulletins are to achieve the same accuracy as that possible using contextual methods (e.g Myers et al. 2011; Nooshiri et al. 
2017) then we need to find ways of applying and presenting the necessary corrections and associated uncertainties.

\section{ACKNOWLEDGMENTS}

This work was partly supported by the Air Force Research Laboratory under contract FA9453-16-C0006.

We are grateful to Øvind Engen for providing the earthquake catalogs used in his 2003 study.

Most maps and figures in this paper are created using GMT software (Wessel \& Smith 1995).

The Bayesloc multiple event location software and documentation is available from

https://www-gs.llnl.gov/about/nuclear-threat-reduction/nuclear-explosion-monitoring/bayesloc

(last accessed August 2017).

Seismic data from the SPITS and ARCES arrays is available from http://www.norsardata.no/NDC/data/autodrm.html (last accessed August 2017).

Waveform data from the Greenland stations is available under networks GE and DK from http://geofon.gfzpotsdam.de/waveform/ (last accessed August 2017).

All waveform data from the Norwegian National Seismic Network is available from the University of Bergen: ftp://ftp.geo.uib.no/pub/seismo/DATA/WAVEFORM/ (last accessed August 2017).

The bulletin of the International Seismological Center is available from http://www.isc.ac.uk/ (last accessed August 2017).

The NORSAR regional reviewed bulletin is available from http://www.norsardata.no/NDC/bulletins/regional/ (last accessed August 2017).

We are grateful for very helpful comments from two anonymous reviewers which have significantly improved the manuscript.

\section{REFERENCES}

Antonovskaya, G., Konechnaya, Y., Kremenetskaya, E. O., Asming, V., Kværna, T., Schweitzer, J., \& Ringdal, F., 2014, Enhanced Earthquake Monitoring in the European Arctic, Polar Science, 9, 158-167.

Asming, V. E., Baranov, S. V., Vinogradov, Y., \& Voronin, A. I., 2013, Seismic and infrasonic monitoring on the Spitsbergen archipelago, Seismic Instruments, 49(3), 209-218.

Baggeroer, A. B., Kuperman, W. A., \& Mikhalevsky, P. N., 1993, An overview of matched field methods in ocean acoustics, IEEE Journal of Oceanic Engineering, 18(4), 401-424.

Ballard, S., Hipp, J. R., Begnaud, M. L., Young, C. J., Encarnacao, A. V., Chael, E. P., \& Phillips, W. S., 2016, SALSA3D: A Tomographic Model of Compressional Wave Slowness in the Earth's Mantle for Improved 
Travel-Time Prediction and Travel-Time Prediction Uncertainty, Bulletin of the Seismological Society of America, 106, 2900-2916.

Baumgardt, D. R., 2001, Sedimentary basins and the blockage of Lg wave propagation in the continents, Pure and applied geophysics, 158, 1207-1250, doi:10.1007/PL00001221.

Ben Horin, Y., Koch, K., \& Bartal, Y., 2004, Use of GSETT-3 gamma data in the Slowness-Azimuth Calibration of IMS primary arrays at regional distances, Journal of Seismology, 8, 129-142.

Berteussen, K. A., 1976, The origin of slowness and azimuth anomalies at large arrays, Bulletin of the Seismological Society of America, 66, 719-741.

Billings, S. D., Sambridge, M. S., \& Kennett, B. L. N., 1994, Errors in hypocenter location: Picking, model, and magnitude dependence, Bulletin of the Seismological Society of America, 84(6), 1978-1990.

Bondár, I. \& Storchak, D., 2011, Improved location procedures at the International Seismological Centre, Geophysical Journal International, 186(3), 1220-1244.

Bondár, I., North, R. G., \& Beall, G., 1999, Teleseismic slowness-azimuth station corrections for the International Monitoring System Seismic Network, Bulletin of the Seismological Society of America, 89(4), 9891003.

Bondár, I., Myers, S. C., Engdahl, E. R., \& Bergman, E. A., 2004, Epicentre accuracy based on seismic network criteria, Geophysical Journal International, 156(3), 483-496.

Bratt, S. R. \& Bache, T. C., 1988, Locating events with a sparse network of regional arrays, Bulletin of the Seismological Society of America, 78(2), 780-798.

Bungum, H., Ritzmann, O., Maercklin, N., Faleide, J. I., Mooney, W. D., \& Detweiler, S. T., 2005, ThreeDimensional Model for the Crust and Upper Mantle in the Barents Sea Region, EOS, Transactions American Geophysical Union, 86, 160-161.

Campillo, M., 1987, $\mathrm{Lg}$ wave propagation in a laterally varying crust and the distribution of the apparent quality factor in central France, Journal of Geophysical Research, 92(B12), 12604-12614.

Clinton, J. F., Nettles, M., Walter, F., Anderson, K., Dahl-Jensen, T., Giardini, D., Govoni, A., Hanka, W., Lasocki, S., Lee, W. S., McCormack, D., Mykkeltveit, S., Stutzmann, E., \& Tsuboi, S., 2014, Seismic Network in Greenland Monitors Earth and Ice System, Eos Trans. AGU, 95(2), 13-14.

Czuba, W., Grad, M., Guterch, A., Majdański, M., Malinowski, M., Mjelde, R., Moskalik, M., Środa, P., WildePiórko, M., \& Nishimura, Y., 2008, Seismic crustal structure along the deep transect Horsted'05, Svalbard, Polish Polar Research, 29(3), 279-290.

Czuba, W., Grad, M., Mjelde, R., Guterch, A., Libak, A., Krüger, F., Murai, Y., Schweitzer, J., \& the IPY Project Group, 2011, Continentocean-transition across a trans-tensional margin segment: off Bear Island, Barents Sea, Geophysical Journal International, 184(2), 541-554.

Demuth, A., Ottemöller, L., \& Keers, H., 2016, Ambient noise levels and detection threshold in Norway, Journal of Seismology, 20(3), 889-904.

Douglas, A., 1967, Joint Epicentre Determination, Nature, 215(5096), 47-48.

Douglas, A., 2002, Seismometer Arrays - Their Use in Earthquake and Test Ban Seismology, in International 
Handbook of Earthquake and Engineering Seismology, edited by W. H. K. Lee, H. Kanamori, P. C. Jennings, \& C. Kisslinger, pp. 357-367, Academic Press.

Engdahl, R. E., van der Hilst, R., \& Buland, R., 1998, Global teleseismic earthquake relocation with improved travel times and procedures for depth determination, Bulletin of the Seismological Society of America, 88, $722-743$.

Engen, Ø.., Eldholm, O., \& Bungum, H., 2003, The Arctic plate boundary, Journal of Geophysical Research Solid Earth, 108(B2), 2075+.

Furumura, T., Hong, T.-K., \& Kennett, B. L. N., 2014, Lg wave propagation in the area around Japan: observations and simulations, Progress in Earth and Planetary Science, 1(1), 1-20.

Gibbons, S. J., 2006, On the Identification and Documentation of Timing Errors: An Example at the KBS Station, Spitsbergen, Seism. Res. Lett., 77, 559-571, doi:10.1785/gssrl.77.5.559.

Gibbons, S. J., Kværna, T., \& Ringdal, F., 2010, Considerations in Phase Estimation and Event Location Using Small-Aperture Regional Seismic Arrays, Pure and Applied Geophysics, 167, 381-399.

Gibbons, S. J., Schweitzer, J., Ringdal, F., Kværna, T., Mykkeltveit, S., \& Paulsen, B., 2011, Improvements to Seismic Monitoring of the European Arctic Using Three-Component Array Processing at SPITS, Bulletin of the Seismological Society of America, 101(6), 2737-2754.

Gibbons, S. J., Antonovskaya, G., Asming, V., Konechnaya, Y. V., Kremenetskaya, E., Kværna, T., Schweitzer, J., \& Vaganova, N. V., 2016, The 11 October 2010 Novaya Zemlya Earthquake: Implications for Velocity Models and Regional Event Location, Bulletin of the Seismological Society of America, 106(4), 1470-1481.

Harris, D. B., 1990, Comparison of the direction estimation performance of high-frequency seismic arrays and three-component stations, Bulletin of the Seismological Society of America, 80(6B), 1951-1968.

Harris, D. B. \& Kvaerna, T., 2010, Superresolution with seismic arrays using empirical matched field processing, Geophysical Journal International, 182(3), 1455-1477.

Harris, D. B., Gibbons, S. J., Rodgers, A. J., \& Pasyanos, M. E., 2012, Nuclear Test Ban Treaty Verification: Improving Test Ban Monitoring with Empirical and Model-Based Signal Processing, IEEE Signal Processing Magazine, 29(3), 57-70.

Hauser, J., Dyer, K. M., Pasyanos, M. E., Bungum, H., Faleide, J. I., Clark, S. A., \& Schweitzer, J., 2011, A probabilistic seismic model for the European Arctic, Journal of Geophysical Research, 116(B1), B01303+.

Hicks, E. C., Kværna, T., Mykkeltveit, S., Schweitzer, J., \& Ringdal, F., 2004, Travel-times and Attenuation Relations for Regional Phases in the Barents Sea Region, Pure appl. geophys., 161, 1-19.

Jokat, W., Kollofrath, J., Geissler, W. H., \& Jensen, L., 2012, Crustal thickness and earthquake distribution south of the Logachev Seamount, Knipovich Ridge, Geophys. Res. Lett., 39(8), L08302+.

Junek, W. N., Kværna, T., Pirli, M., Schweitzer, J., Harris, D. B., Dodge, D. A., \& Woods, M. T., 2015, Inferring Aftershock Sequence Properties and Tectonic Structure Using Empirical Signal Detectors, Pure and Applied Geophysics, 172(2), 359-373.

Kennett, B. L. N., Engdahl, E. R., \& Buland, R., 1995, Constraints on seismic velocities in the Earth from traveltimes, Geophysical Journal International, 122, 108-124. 
Koch, K. \& Kradolfer, U., 1999, Determination of Mislocation Vectors to Evaluate bias at GSETT-3 primary stations, Journal of Seismology, 3(2), 139-151.

Köhler, A., Nuth, C., Schweitzer, J., Weidle, C., \& Gibbons, S. J., 2015, Regional passive seismic monitoring reveals dynamic glacier activity on Spitsbergen, Svalbard, Polar Research, 34.

Korger, E. I. M. \& Schlindwein, V., 2012, Performance of localization algorithms for teleseismic mid-ocean ridge earthquakes: the 1999 Gakkel Ridge earthquake swarm and its geological interpretation, Geophysical Journal International, 188(2), 613-625.

Korger, E. I. M. \& Schlindwein, V., 2013, Seismicity and structure of the 85E volcanic complex at the ultraslow spreading Gakkel Ridge from local earthquake tomography, Geophysical Journal International, 196, 539551.

Kværna, T. \& Doornbos, D. J., 1991, Scattering of Regional Pn by Moho Topography, Geophysical Research Letters, 18, 1273-1276, doi:10.1029/91GL01292.

Kværna, T. \& Ringdal, F., 2013, Detection Capability of the Seismic Network of the International Monitoring System for the Comprehensive Nuclear-Test-Ban Treaty, Bulletin of the Seismological Society of America, 103, 759-772.

Letort, J., Vergoz, J., Guilbert, J., Cotton, F., Sebe, O., \& Cano, Y., 2014, Moderate Earthquake Teleseismic Depth Estimations: New Methods and Use of the Comprehensive Nuclear-Test-Ban Treaty Organization Network Data, Bulletin of the Seismological Society of America, 104(2), 593-607.

Lin, G. \& Shearer, P., 2005, Tests of relative earthquake location techniques using synthetic data, Journal of Geophysical Research, 110(B4), B04304+.

Morozov, A. N., Vaganova, N. V., Ivanova, E. V., Konechnaya, Y. V., Fedorenko, I. V., \& Mikhaylova, Y. A., 2016, New data about small-magnitude earthquakes of the ultraslow-spreading Gakkel Ridge, Arctic Ocean, Journal of Geodynamics, 93, 31-41.

Murphy, J. R., Rodi, W., Johnson, M., Sultanov, D. D., Bennett, T. J., Toksöz, M. N., Ovtchinnikov, V., Barker, B. W., Reiter, D. T., Rosca, A. C., \& Shchukin, Y., 2005, Calibration of International Monitoring System (IMS) Stations in Central and Eastern Asia for Improved Seismic Event Location, Bulletin of the Seismological Society of America, 95(4), 1535-1560.

Myers, S. C., Johannesson, G., \& Hanley, W., 2007, A Bayesian hierarchical method for multiple-event seismic location, Geophysical Journal International, 171(3), 1049-1063.

Myers, S. C., Johannesson, G., \& Hanley, W., 2009, Incorporation of probabilistic seismic phase labels into a Bayesian multiple-event seismic locator, Geophysical Journal International, 177, 193-204.

Myers, S. C., Begnaud, M. L., Ballard, S., Pasyanos, M. E., Phillips, W. S., Ramirez, A. L., Antolik, M. S., Hutchenson, K. D., Dwyer, J. J., Rowe, C. A., \& Wagner, G. S., 2010, A Crust and Upper-Mantle Model of Eurasia and North Africa for Pn Travel-Time Calculation, Bulletin of the Seismological Society of America, $100(2), 640-656$.

Myers, S. C., Johannesson, G., \& Simmons, N. A., 2011, Global-scale P wave tomography optimized for prediction of teleseismic and regional travel times for Middle East events: 1. Data set development, Journal 
of Geophysical Research, 116(B4), B04304+.

Myers, S. C., Simmons, N. A., Johannesson, G., \& Matzel, E., 2015, Improved Regional and Teleseismic P-Wave Travel-Time Prediction and Event Location Using a Global 3D Velocity Model, Bulletin of the Seismological Society of America, 105(3), 1642-1660.

Mykkeltveit, S. \& Ringdal, F., 1981, Phase identification and event location at regional distances using smallaperture array data, in Identification of seismic sources - Earthquake or underground explosions, edited by E. S. Husebye \& S. Mykkeltveit, pp. 467-481, Reidel Publishing Company.

Mykkeltveit, S., Ringdal, F., Kværna, T., \& Alewine, R. W., 1990, Application of regional arrays in seismic verification research, Bull Seism Soc Am, 80, 1777-1800.

Nooshiri, N., Saul, J., Heimann, S., Tilmann, F., \& Dahm, T., 2017, Revision of earthquake hypocentre locations in global bulletin data sets using source-specific station terms, Geophysical Journal International, 208(2), 589-602.

Oliver, J. \& Murphy, L., 1971, WWSSN: Seismology's Global Network of Observing Stations, Science, 174(4006), 254-261.

Pirli, M., Schweitzer, J., Ottemöller, L., Raeesi, M., Mjelde, R., Atakan, K., Guterch, A., Gibbons, S. J., Paulsen, B., Debski, W., Wiejacz, P., \& Kvaerna, T., 2010, Preliminary Analysis of the 21 February 2008 Svalbard (Norway) Seismic Sequence, Seismological Research Letters, 81(1), 63-75.

Pirli, M., Schweitzer, J., \& Paulsen, B., 2013, The Storfjorden, Svalbard, 2008-2012 aftershock sequence: Seismotectonics in a Polar environment, Tectonophysics, 601, 192-205.

Prieto, G. A., Parker, R. L., \& Vernon, F. L., 2009, A Fortran 90 library for multitaper spectrum analysis, Computers \& Geosciences, 35(8), 1701-1710, doi: 10.1016/j.cageo.2008.06.007.

Richards-Dinger, K. B. \& Shearer, P. M., 2000, Earthquake locations in southern California obtained using source-specific station terms, Journal of Geophysical Research, 105(B5), 10939-10960.

Schlindwein, V., Demuth, A., Geissler, W. H., \& Jokat, W., 2013, Seismic gap beneath Logachev Seamount: Indicator for melt focusing at an ultraslow mid-ocean ridge?, Geophys. Res. Lett., 40(9), 1703-1707.

Schweitzer, J., 2001, HYPOSAT - An Enhanced Routine to Locate Seismic Events, Pure and Applied Geophysics, 158, 277-289.

Schweitzer, J., 2001, Slowness Corrections - One Way to Improve IDC Products, Pure appl. geophys., 158, 375-396.

Schweitzer, J., 2014, Seismometer Arrays, in Encyclopedia of Earthquake Engineering, edited by M. Beer, I. A. Kougioumtzoglou, E. Patelli, \& I. S. Au, pp. 1-11, Springer Berlin Heidelberg.

Simmons, N. A., Myers, S. C., Johannesson, G., \& Matzel, E., 2012, LLNL-G3Dv3: Global P wave tomography model for improved regional and teleseismic travel time prediction, J. Geophys. Res., 117(B10), B10302+.

Simmons, N. A., Myers, S. C., Johannesson, G., Matzel, E., \& Grand, S. P., 2015, Evidence for long-lived subduction of an ancient tectonic plate beneath the southern Indian Ocean, Geophys. Res. Lett., 42(21), 2015GL066237+. 
Wang, J., Templeton, D. C., \& Harris, D. B., 2015, Discovering new events beyond the catalogue: application of empirical matched field processing to Salton Sea geothermal field seismicity, Geophysical Journal International, 203(1), 22-32.

Wessel, P. \& Smith, W. H. F., 1995, New version of the Generic Mapping Tools, EOS Trans. Am. Geophys. Union, 76, 329.

Wilde-Piórk, M., Grad, M., Wiejacz, P., \& Schweitzer, J., 2009, HSPB seismic broadband station in Southern Spitsbergen: First results on crustal and mantle structure from receiver functions and SKS splitting, Polish Polar Research, 30(4), 301-316. 


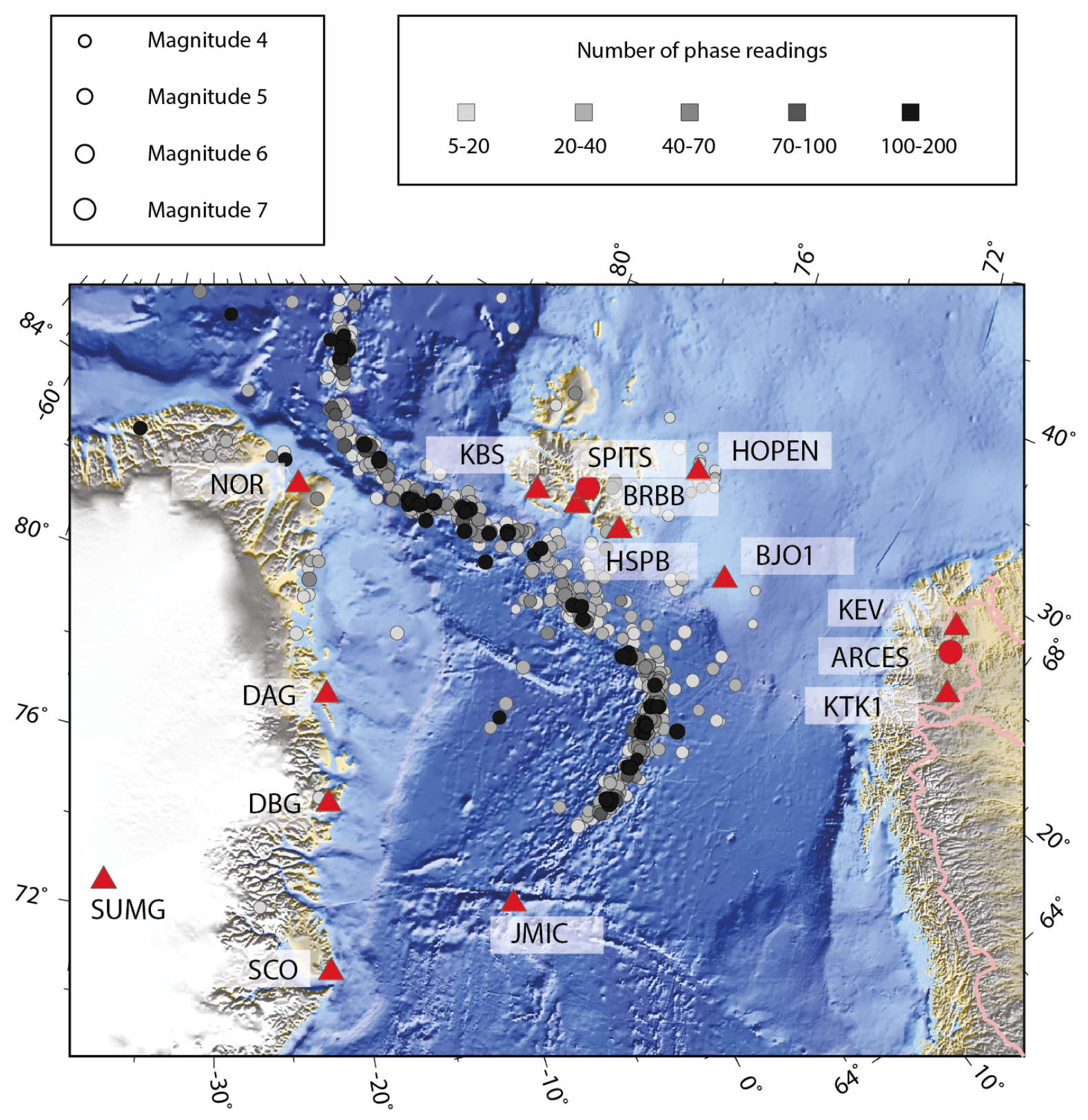

Figure 1. Events North of 72 degrees from Engen et al. (2003) together with stations in the current network which are most sensitive to low-magnitude events on the spreading ridge. The events are marked using circles with size proportional to magnitude and with the shade a function of the number of associated phase readings (essentially all teleseismic) as indicated. Permanent 3-component stations (triangles) and arrays (circles) are shown in red. 


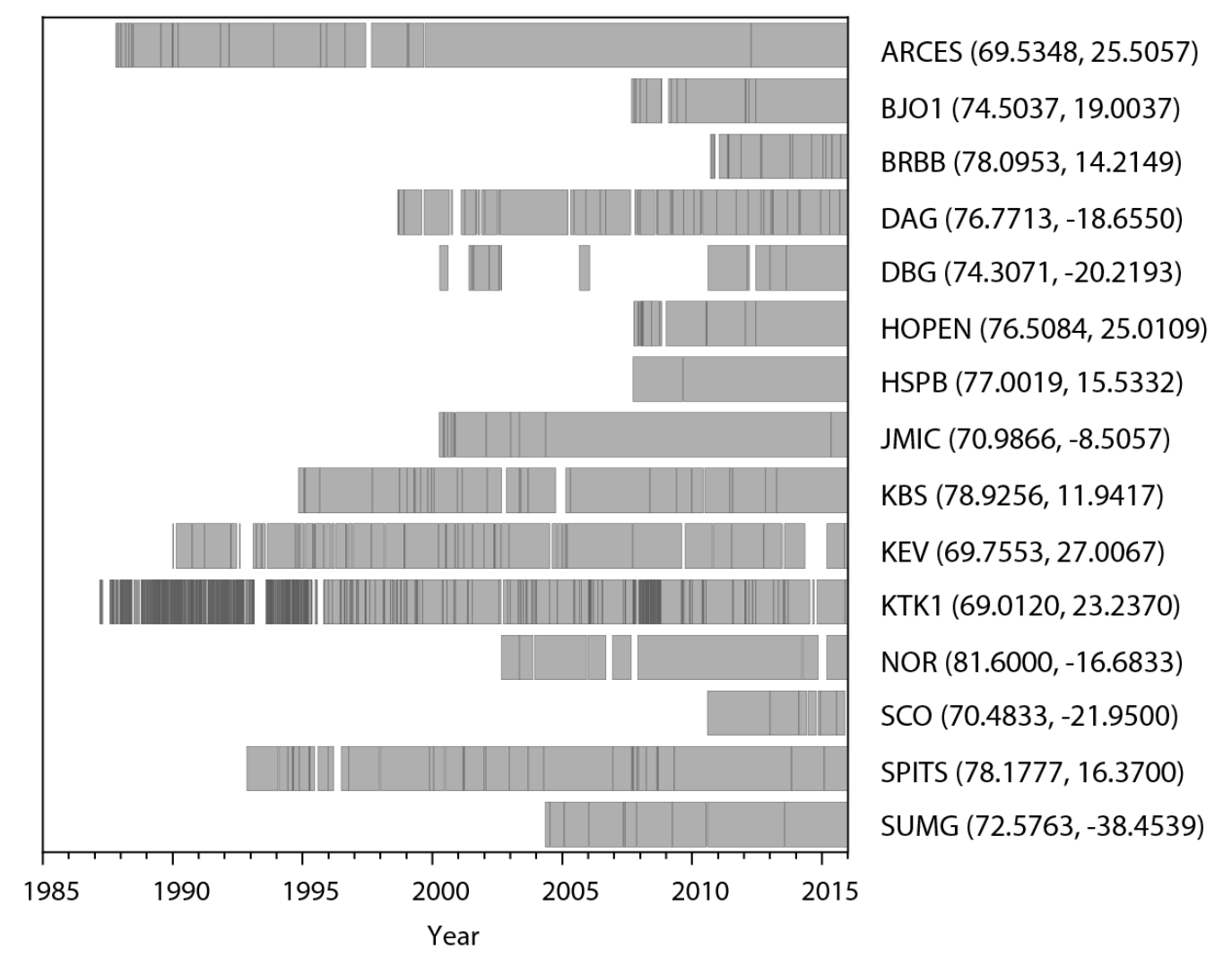

Figure 2. Overview of time-intervals over which data from the stations displayed in Fig. 1 have digital data in the archives. Almost all of this data is continuous except for a few stations for which data before 2009 is in triggered segemnts. Gaps in the bars indicate data gaps of 24 hours or more and time spans for which the bars appear darker contain many long gaps. 


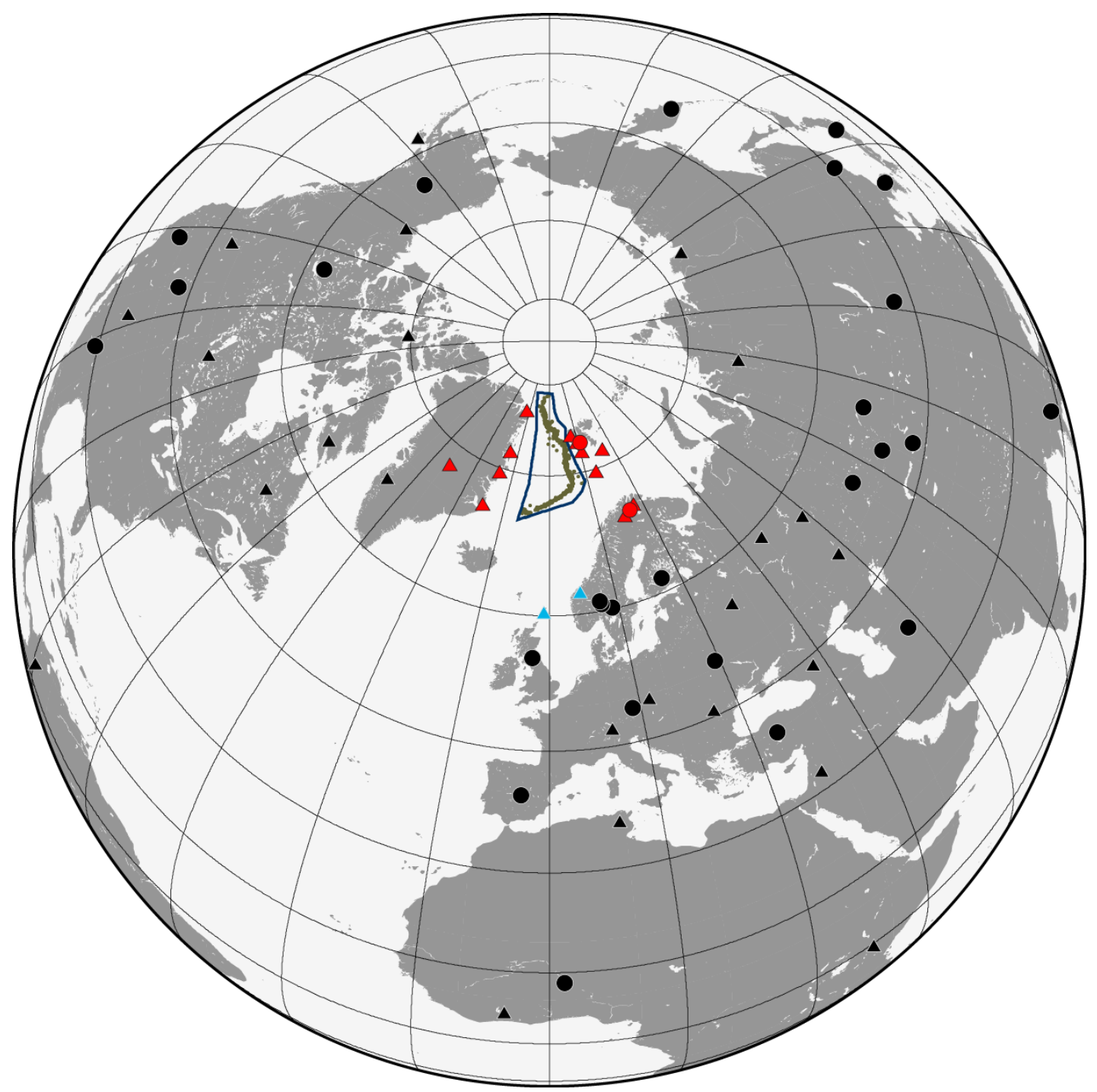

Figure 3. Global map showing ridge seismicity in the region of interest from $70^{\circ} \mathrm{N}$ to $84^{\circ} \mathrm{N}$ together with the regional network displayed in Fig. 1 (in red) and arrays (circles) and 3-component stations (triangles) of the International Monitoring System. (Two non-IMS stations - AKN and LRW - are coloured blue and are part of the regional network but not shown in Fig. 1.) 
a)

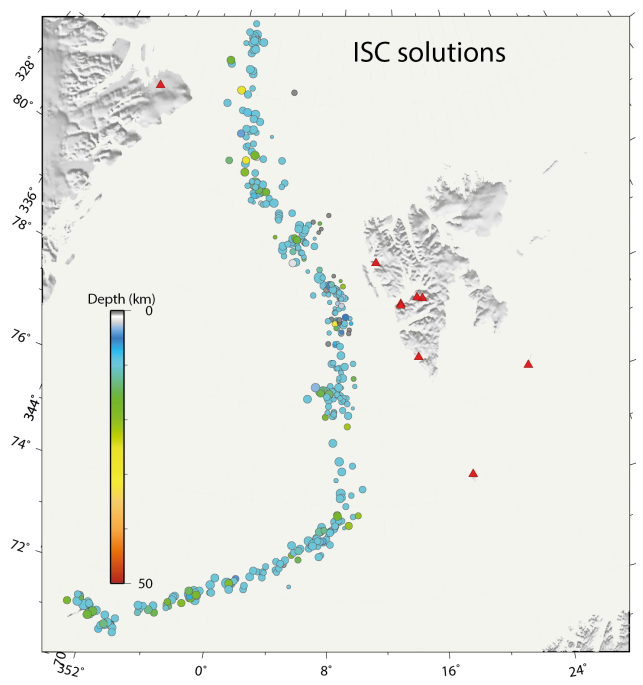

c)

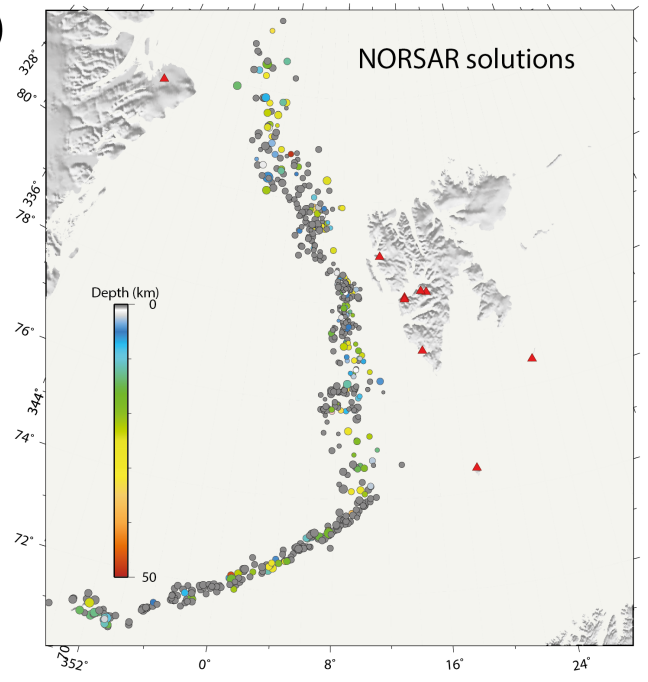

b)

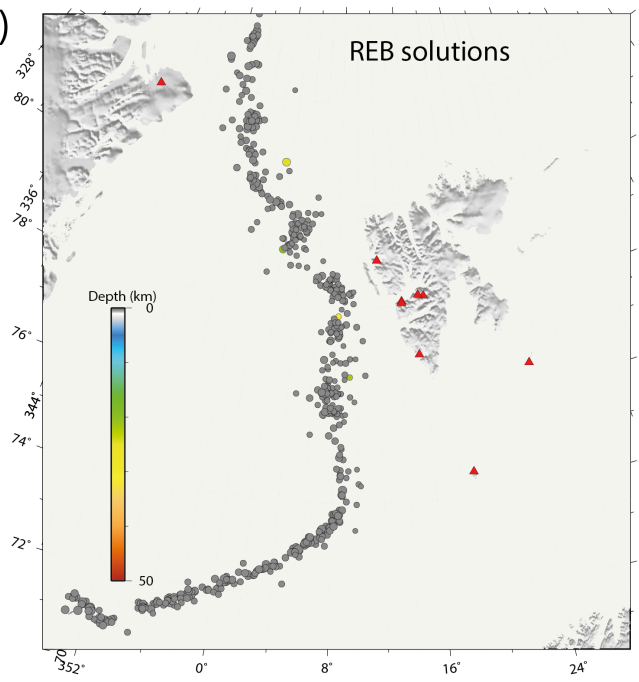

d)

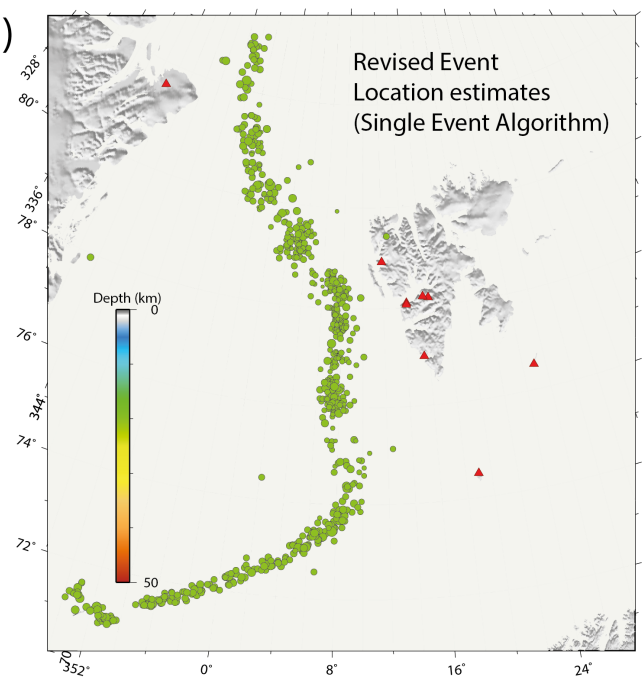

Figure 4. Selected event locations on the mid-Atlantic ridge between 70 and 84 degrees North from (a) the catalog of the International Seismological Center (ISC), (b) the Reviewed Event Bulletin (REB) of the Comprehensive Nuclear-Test-Ban Treaty Organization, (c) the NORSAR regional reviewed event bulletin, and (d) fixed-depth solutions using a single-event algorithm for relocated events in the current study. 
a)

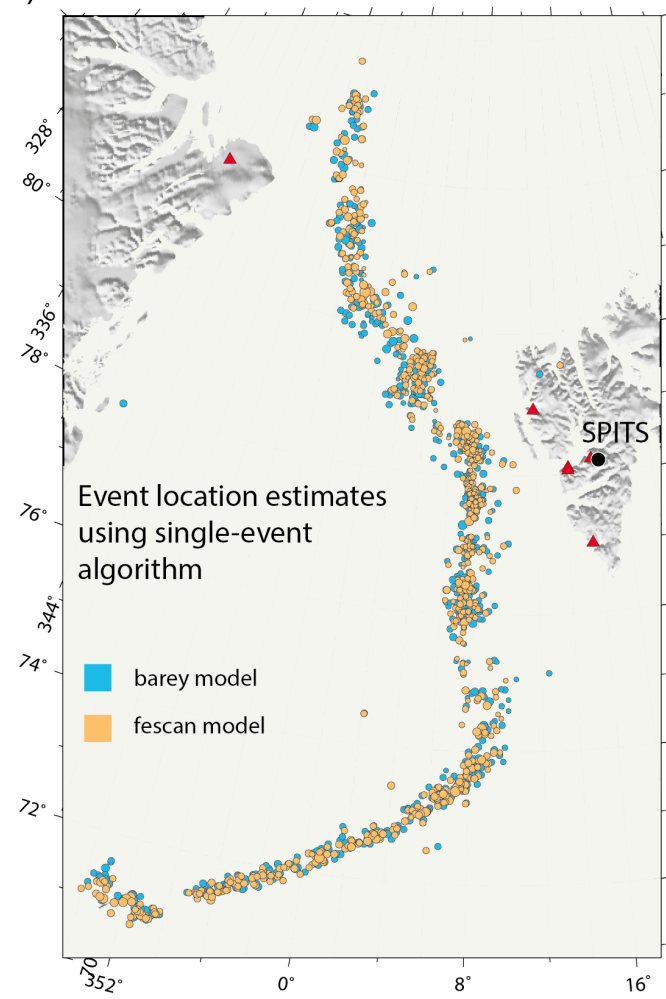

c)

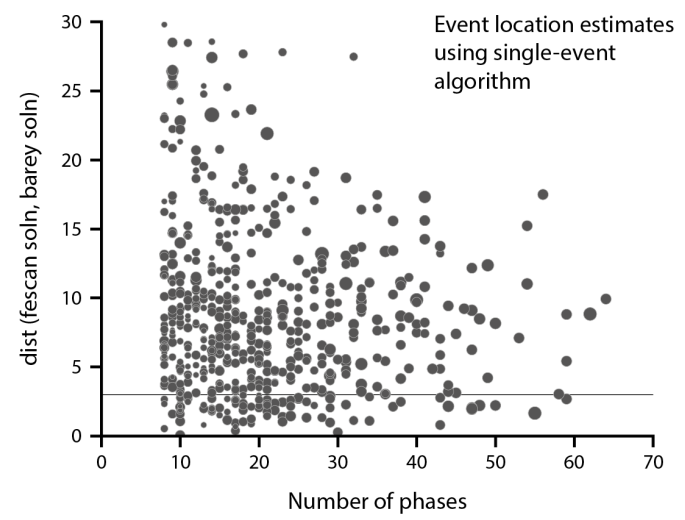

b)

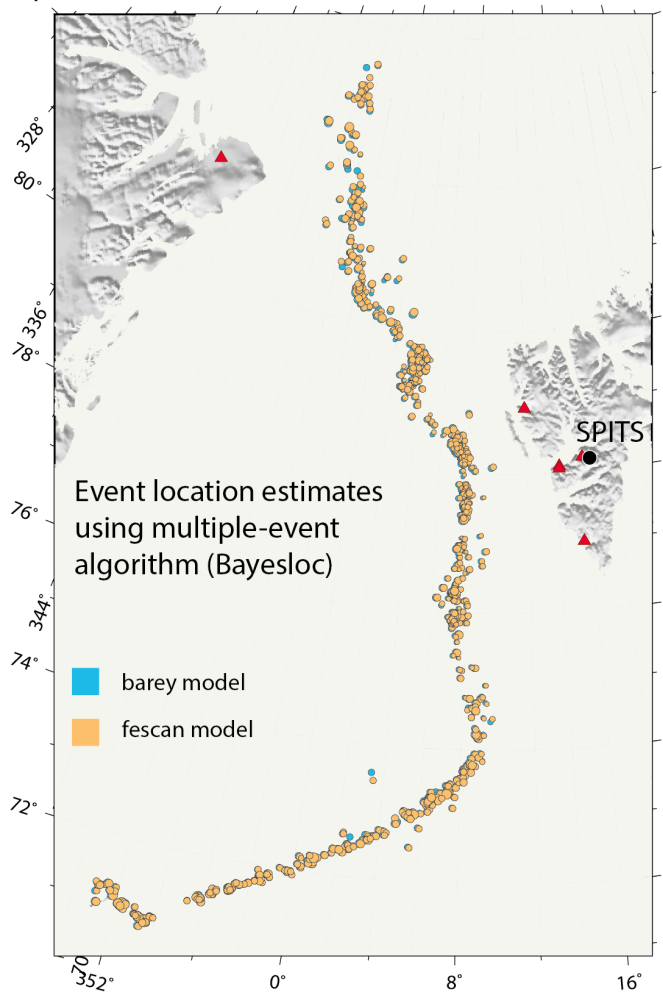

d)

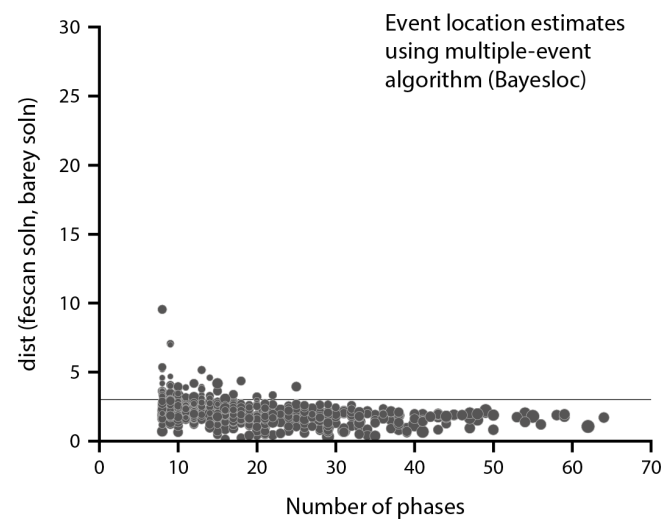

Figure 5. Relocated seismicity with both barey and Fennoscandia models using (a) a single event location algorithm and (b) Bayesloc. For each event, the distance in km between the barey solution and the Fennoscandia solution is plotted as a function of the number of defining phases in panels (c) and (d). 
a)

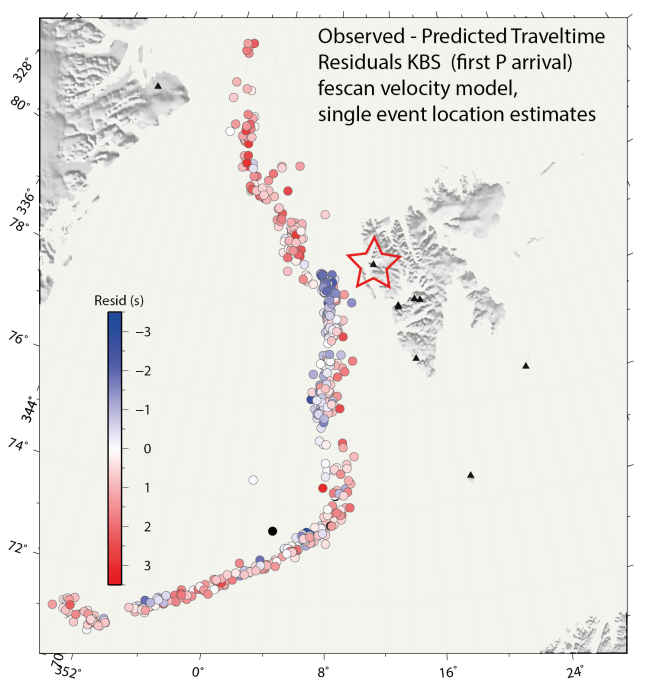

c)

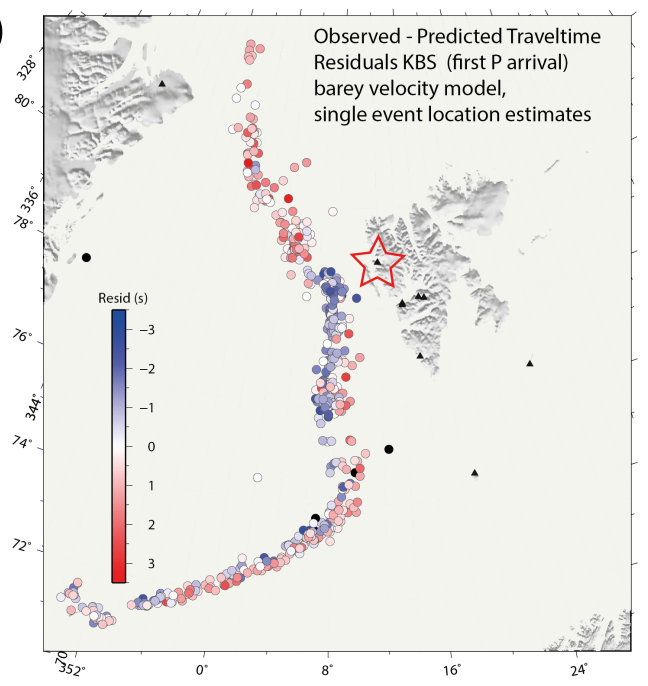

b)

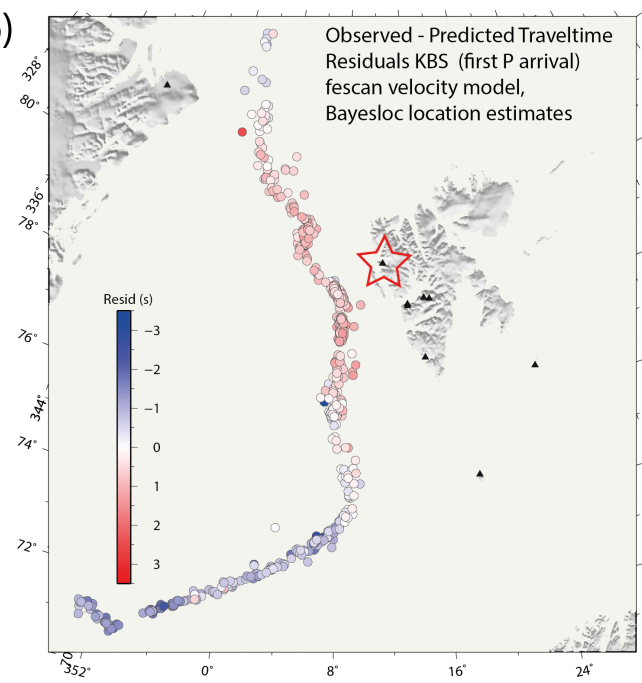

d)

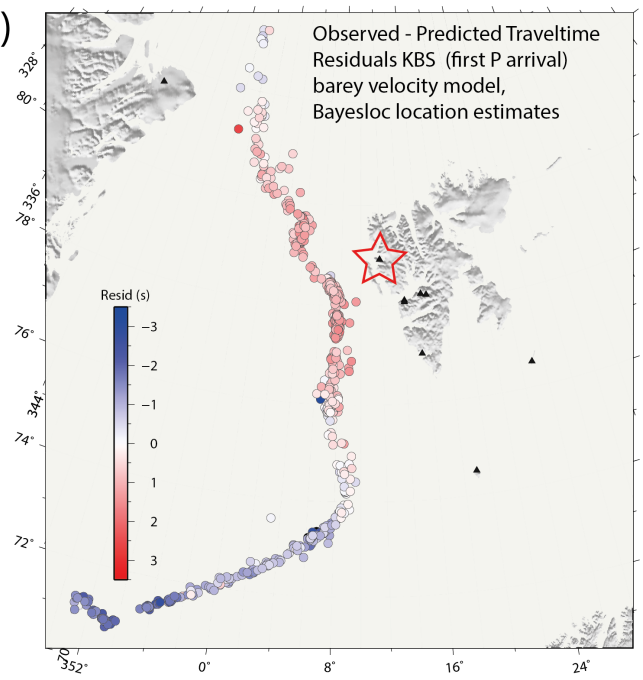

Figure 6. Observed minus predicted travel-time residuals for the first regional P-wave arrival at KBS (highlighted with a red star) from the event hypocenter and origin times solved for using velocity models and location algorithms as indicated. A blue symbol means that the signal arrives earlier than the model predicts it to, that the predicted traveltime is too long, that the model velocities along the path taken are too slow. 
a)

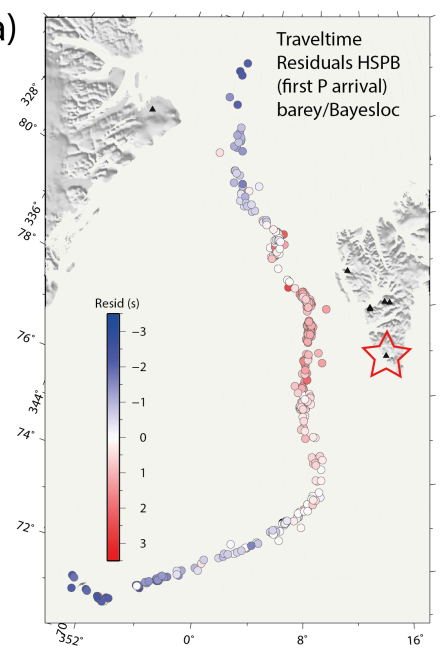

b)

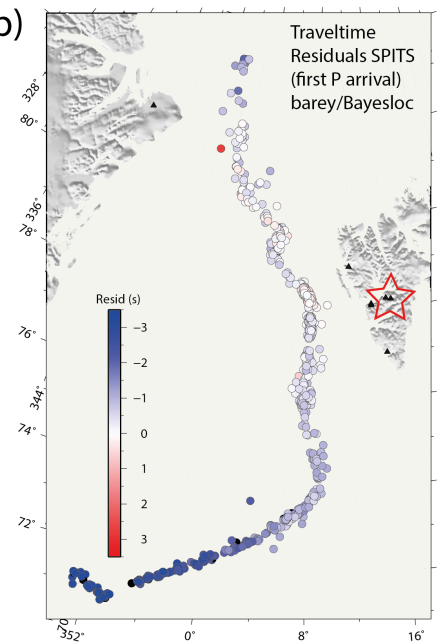

c)

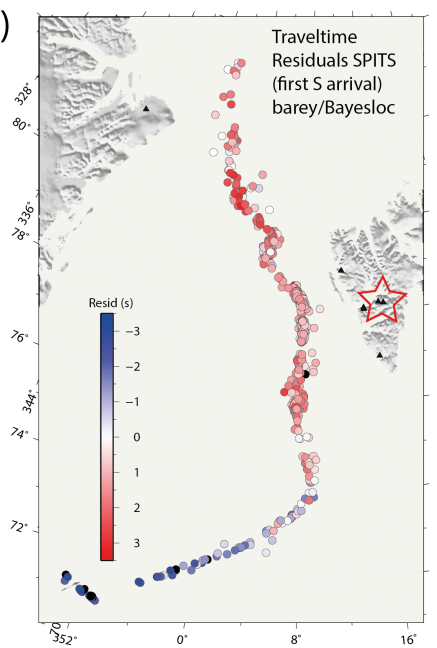

Figure 7. Observed minus predicted travel-time residuals for (a) the first P-arrival at HSPB, (b) the first Parrival at SPITS, and (c) the first S-arrival at SPITS for the event hypocenter and origin time means for the Barey velocity model calculations displayed in Fig. 5 b) obtained using the Bayesloc program. 


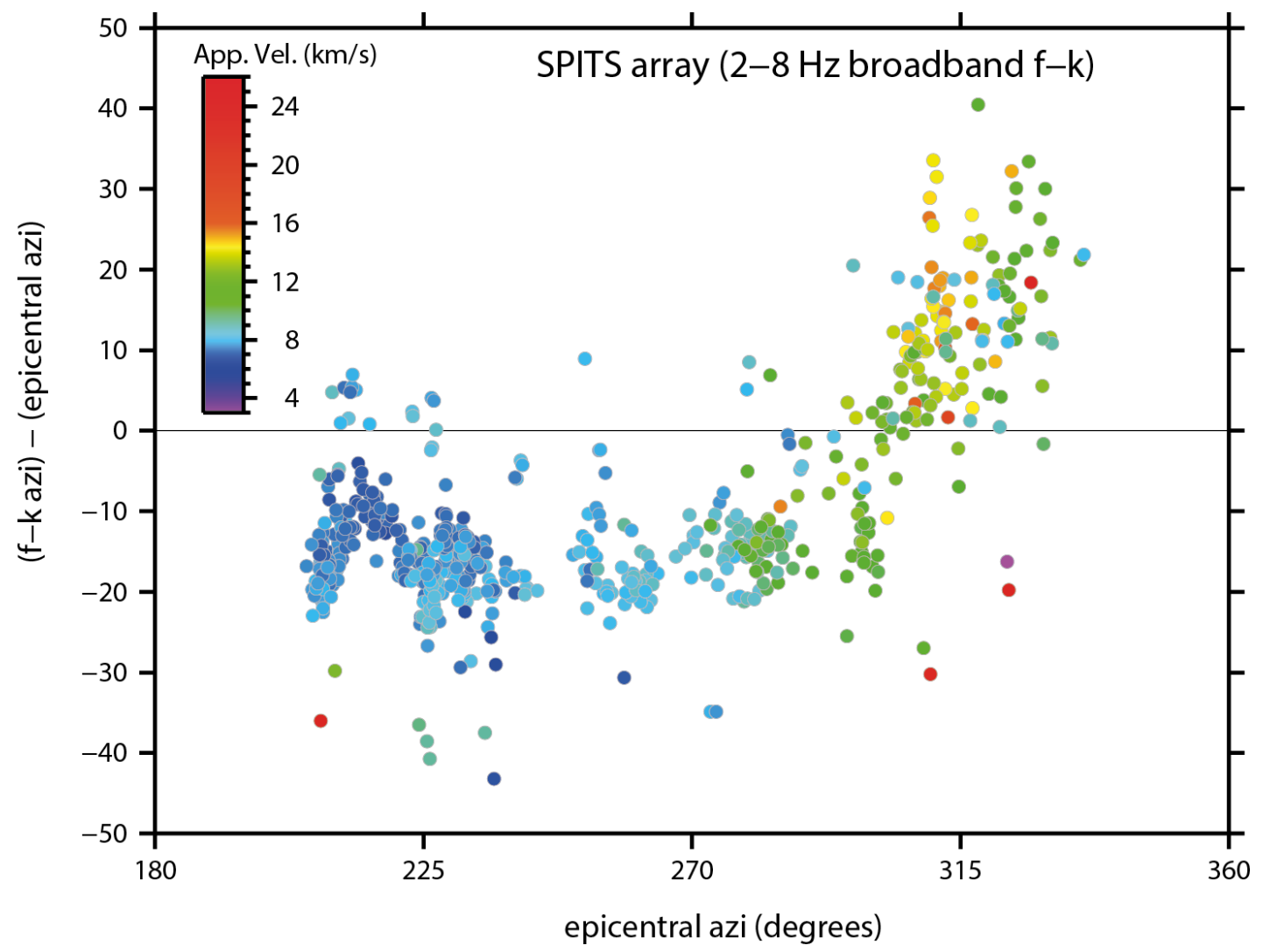

Figure 8. Observed minus predicted backazimuth residuals for first P-arrivals from the Bayesloc-located events displayed in Fig. 5 b). Epicentral azimuth refers to the great-circle backazimuth from the SPITS array to the Bayesloc-determined epicenters. The f-k backazimuth estimates are measured using a 3 second long data segment in the $2-8 \mathrm{~Hz}$ frequency band. 


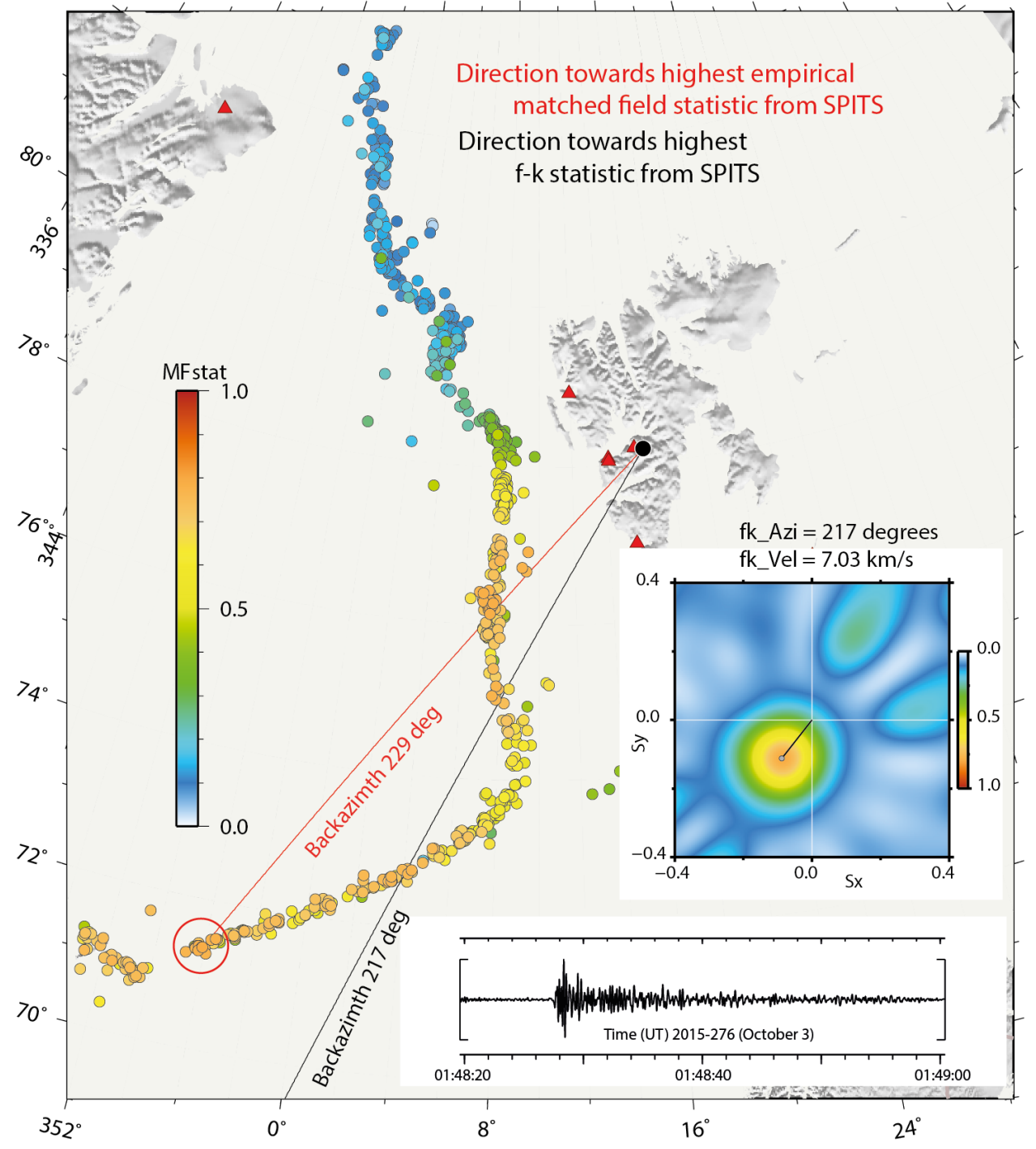

Figure 9. Matched field statistic evaluated on the SPITS array at a time 2015-276:01.48.27.425 as a function of the location of the template events together with the best estimate of the true location of the event at 2015276:01.46.24. The backazimuth as indicated by the classical $\mathrm{f}-\mathrm{k}$ analysis (plane wave) estimate is displayed. 
a)

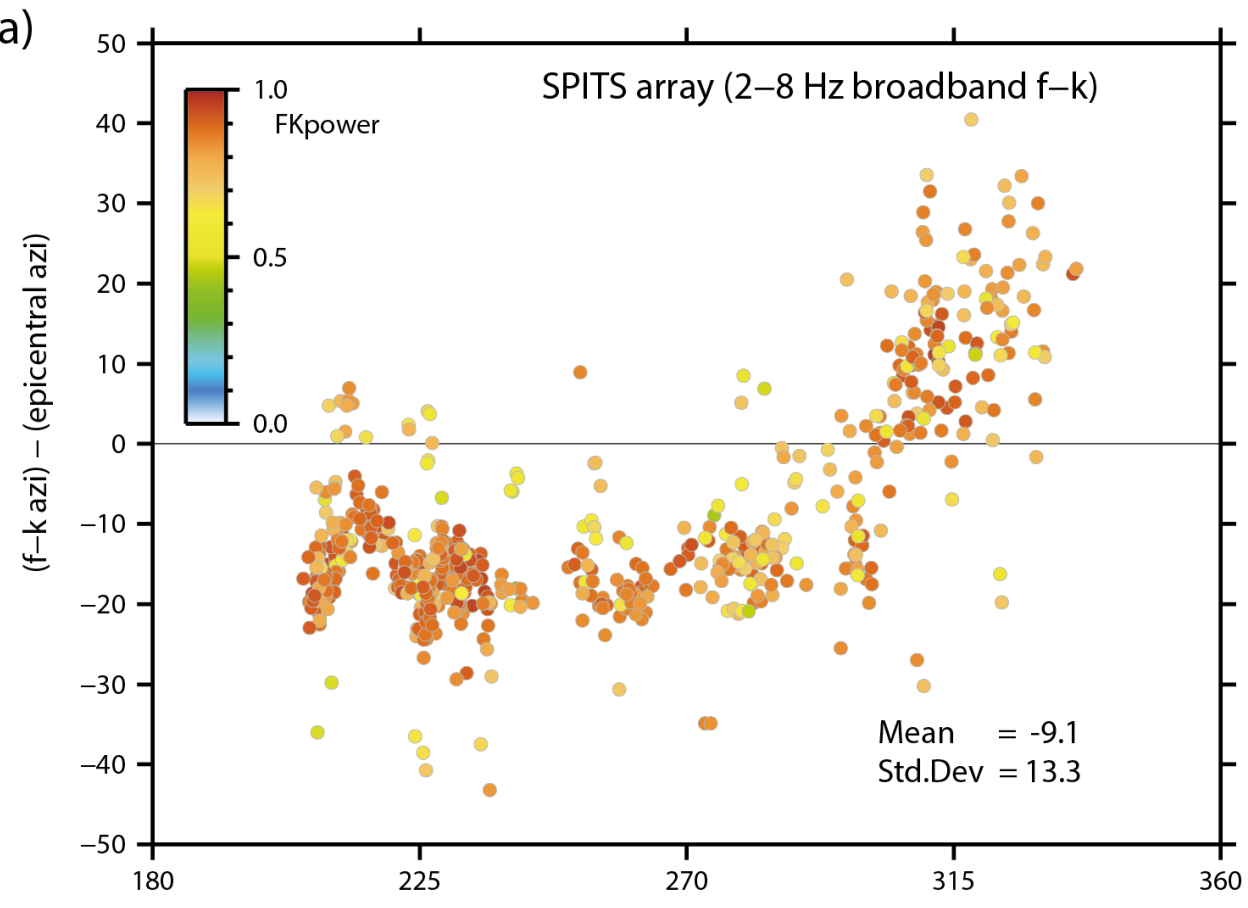

b)

epicentral azi (degrees)

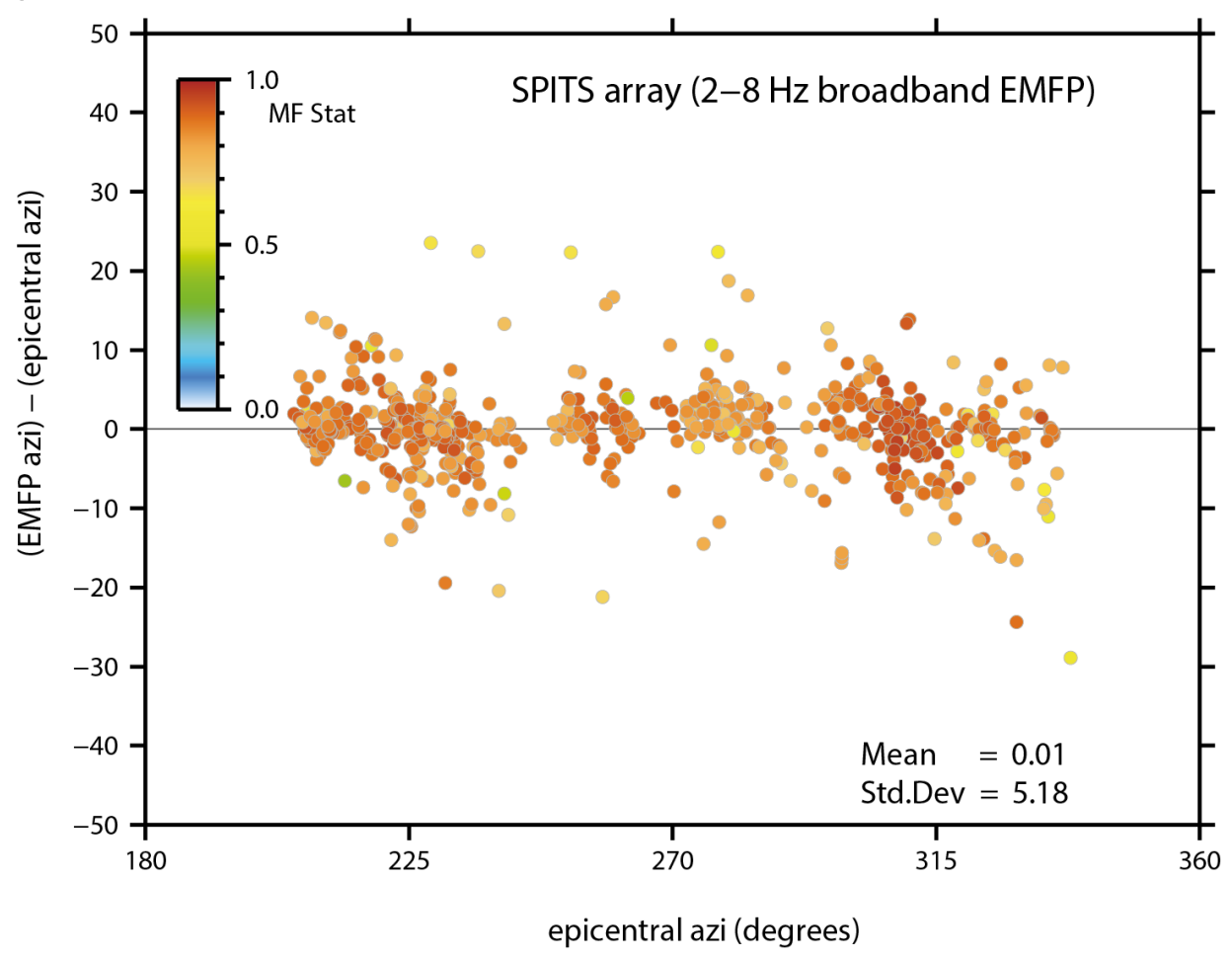

Figure 10. Backazimuth estimates for first P-arrivals at SPITS from the Bayesloc-located events displayed in Fig. 5 b) using (a) classical f-k analysis and (b) a matched field comparison with the templates evaluated from each of the other events. Panel (a) is almost identical to Fig. 8 except that the colour of each symbol indicates the relative power rather than the apparent velocity. In panel (b), for a given event, the matched field statistic for the first P-arrival has been calculated against the P-arrival for every other event (as displayed for a single event in Fig. 9); the epicentral azimuth of the event with the best match is used to calculate the residual. 